\title{
Waverider configurations derived from general conical flowfields
}

\author{
Kai Cui • Dongxu Zhao • Guowei Yang
}

Received: 18 September 2006 / Revised: 5 December 2006 / Accepted: 13 December 2006 / Published online: 22 May 2007

(c) Springer-Verlag 2007

\begin{abstract}
A method based on the computational fluid dynamics (CFD) is presented for a flexible waverider's design. The generating bodies of this method could be any cones. In addition, either the leading edge or the profile of the scramjet's inlet is used as the waverider's definition curve, parameterized by the quadric function, the sigmoid function or the B-spline function. Furthermore, several numerical examples are carried out to validate the method and the relevant codes. The CFD results of the configurations show that all the designs are successful. Moreover, primary suggestions are proposed for practical design by comparing the geometrical and aerodynamic performances of the conederived waveriders at Mach 6.
\end{abstract}

Keywords Waverider - Hypersonic Computational fluid dynamics

The project supported by the National Natural Science Foundation of China (10502053, 10372106 and 10402043), K. C. Wong Education Foundation of Hong Kong, the Key Laboratory of High Temperature Gas Dynamics of Chinese Academy of Sciences and the State Key Laboratory of Structural Analysis for Industrial Equipment of Dalian University of Technology.

K. Cui · G. Yang

Key Laboratory of High Temperature Gas Dynamics, Institute of Mechanics, Chinese Academy of Sciences, Beijing 100080, China

\section{K. Cui (凶)}

State Key Laboratory of Structural Analysis for Industrial Equipment, Dalian University of Technology,

Dalian 116023, China

e-mail: kcui@imech.ac.cn

D. Zhao

Weihai Bureau of Information Industry,

Weihai 264200, China

\section{Introduction}

Hypersonic flight vehicles and its relative technologies have attracted lots of attention of scientists and engineers. Although great progress has been made in this area, some problems are not well solved yet. One of them is the so-called "lift to drag barrier" [1], i.e. the wave drag and the skin friction will increase drastically for a generic vehicle configuration with the increase of the flight speed in the high altitude. Therefore, it is very difficult to obtain a high lift to drag ratio $(L / D)$. A promising candidate to break down the lift to drag barrier is the waverider configuration, which was introduced by Nonweiler [2] in 1959. A waverider is a type of hypersonic lifting body. When flying at its design Mach number, the entire bow shock is attached to the leading edge (LE) of the body, so there is no flow spillage from the lower surface to the upper surface accordingly. As a result, the high pressure behind the shock wave leads to a considerably higher $L / D$ than that for a generic shape. Because the vehicle appears to be riding on top of the attached shock wave when flying at its design point, hence it is dubbed the "waverider".

Many scientists contributed to the study of waveriders. By choosing the flow field behind a planar oblique shock wave, Nonweiler [2] designed the waverider with a caret-shaped cross-section and a delta planform. In a similar manner, waveriders were generated from circular, inclined circular and elliptic cones by Jones et al. [3] and Rasmussen et al. [4-6], using hypersonic small-disturbance theory. With the development of computers and numerical algorithms, the idea of the waverider generation was extended to complicated flowfields by the aid of the computational fluid dynamics (CFD). For example, axisymmetric power-law shapes were investigated as generating bodies by Corda et al. [7] to pursue higher $L / D$ waverider forms compared with the cones derived ones. 
Takashima et al. [8] constructed waveriders in the flowfield of a blended cone-wedge. In addition, Sabean et al. [9] designed a low drag star body, derived from a 2D power law shape flowfield. Recently, Goonko et al. [10] presented the convergent-flow-derived waveriders, derived from the supersonic or hypersonic axisymmetric flows inside constricting ducts, specifically conical trumpet ducts.

Contrasted with the above flowfield-derived method, the other branch of waverider's design methodology is the osculating cone method, proposed by Sobieczky et al. [11]. On the basis of the strip theory, this method is a shock-based solution that defines the flowfield directly from a specified shockwave and allows the direct selection of scramjet's inlet flowfield while providing good volumetric and packaging. Many scientists have paid great attention to this method [12-14]. But a generic osculating cone waverider might not be exact because the effects of the crossflow are neglected. Lewis et al. [15] improved this method to get the more exact configuration by pressure gradient corrections.

Nowadays, high-speed computers and elaborate CFD algorithms have been developed so tremendously that an exact solution of a complex flowfleld could be obtained within a little time. These advanced techniques are of great benefit to the flowfield-derived waveriders' design and make it become more and more promising. But there are still a few deficiencies in contrast with the osculating cone method. For example, the hypersonic vehicle design is a systematic engineering. Many sub-systems are included, such as the structural system, the thermal protection system and the propulsion system, etc. Therefore, there are various geometrical requirements, not provided by the present configurations. In addition, a hypersonic vehicle driven by the scramjet adopts a forebody-scramjet integrated configuration generally, which requires a nice match between the waverider and the inlet of the scramjet. However, the present configurations defined by an LE often fail to meet this requirement. Naturally, it is urgent to develop a more flexible and practical method of waverider's design. This is the motivation of our work.

In this paper, a waverider's design method is presented on the basis of the CFD analysis. Any type of cones without longitudinal curvature can be selected as the candidates of generating bodies. Furthermore, both the LE and the profile of the inlet of scramjet are used to define a waverider. The latter aims at the match between the forebody and the scramjet. Moreover, the quadric function, the sigmoid function and the B-spline function are employed to parameterize the waverider's definition curve. Hence, the method offers a more powerful design tool than ever.

\section{The waverider design procedure}

A general procedure of generating a waverider is shown in Fig. 1. To begin with, the inviscid hypersonic flowfield around

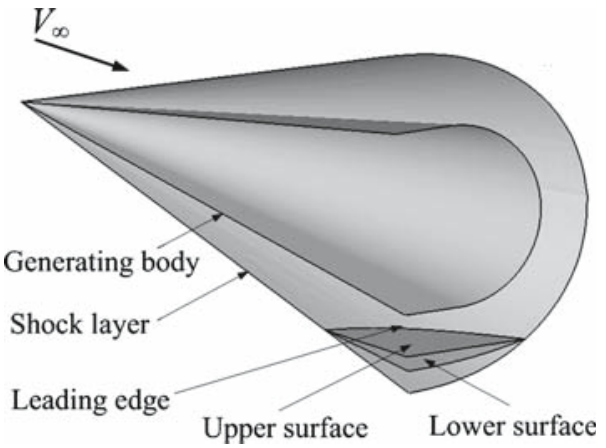

Fig. 1 General sketch of a waverider design

the given generating body is calculated at the design Mach number with the aid of CFD analysis. The shock wave layer can also be captured simultaneously. Next, an LE or a profile of the scramjet's inlet is specified to define a waverider. Afterward, the upper surface of the waverider is constructed by tracing streamlines originated from every point of the LE or the profile of the scramjet's inlet, while the upper surface is usually created by following the freestream through the given or obtained LE to the base of the waverider. Because there is no flow normal to the stream surface, the flowfield around the waverider can be treated as a part of the original flowfield. Besides the design process mentioned above, an evaluated work is often carried on.

\subsection{The inviscid flowfield generation}

The configuration design is based on an inviscid flowfield around the given generating body. Various geometries, such as wedges, circle cones, elliptic cones and power law axisymmetric bodies, have been used as generating bodies successfully. In our work, the generating body can be any conical geometry without longitudinal curvature to further extend the design space. Figure 2 shows a circle cone, a quadrate cone, a cross cone and a floriated cone. It should be emphasized that an arbitrary curve beyond the above illustrations can serve as the cross-section of the conical body.

The inviscid flowfield around the generating body is calculated by numerically solving the Euler equations. This solver is a subset of the Navier-Stokes equations' solver, developed by Yang et al. [16]. A structural grid with $C-H$ topology is utilized to discretize the computational domain. Figure $3 \mathrm{a}$ shows the grids of the floriated cone (corresponding to the Fig. 2d) as an example. Moreover, a solution-based adaptive grid is employed to achieve a good shock resolution. In other words, an estimated position of the shock is taken as the clustered region of the grids at the beginning stage of the computation. After several iterations, the regions with high pressure gradient is captured as the shock wave layer, and the grids are allowed to recluster there. This adaptive operation 
Fig. 2 Four conical bodies. $\mathbf{a}$ the circle cone; $\mathbf{b}$ the quadrate cone; $\mathbf{c}$ the cross cone;

d the floriated cone a

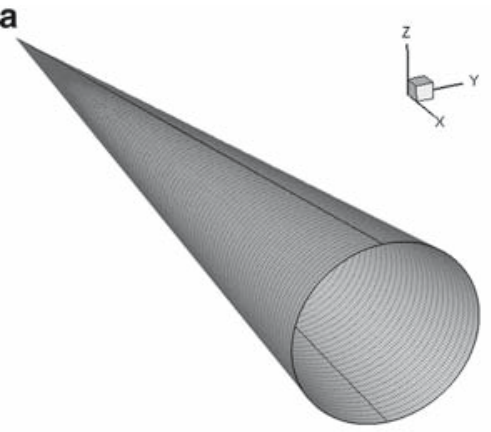

C

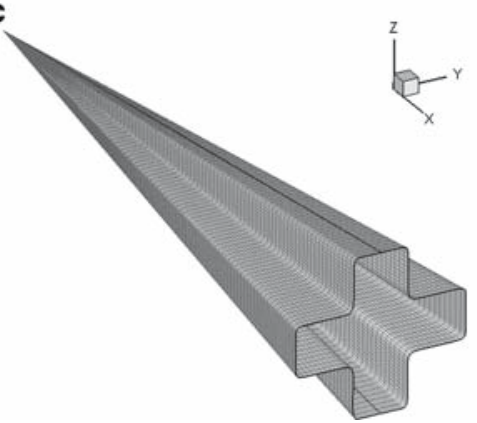

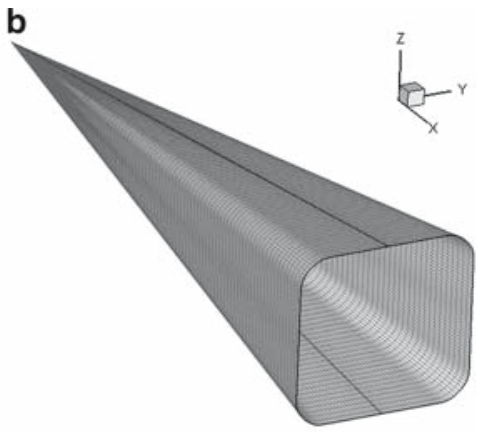

d

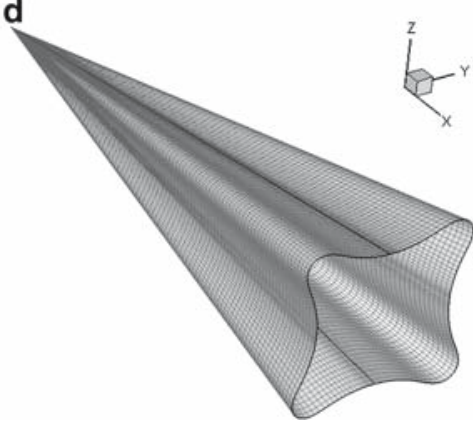

is repeated for 3-5 times until the thickness of the captured shock layer is thin enough. Figure $3 b$ shows the base profile of the initial grids (left) and the ultimate ones (right) of the floriated cone as an instance.

\subsection{Waverider definition}

Previous studies often use the LE as the definition curve of a waverider (shown in Fig. 4a). However, it is difficult to ensure a nice match between the waverider and the scramjet because this method only controls the shape of the LE. To aim at this deficiency, the profile of the scramjet's inlet is also used to define a waverider, shown in Fig. 4b. The lower part of the scramjet's inlet is located on the shock to abide by the rule of integrated design, while the upper part is given discretionarily to meet the design requirement. Therefore, the whole configuration is determined by the shape of the scramjet's inlet uniquely and is satisfied with the demand of integration.

No matter which definition method is adopted, the shape of a waverider is defined by a curve. The profile of the scramjet's inlet is a 2D curve at the base plane (the $Y Z$ plane in Fig. 4). Although the LE is a 3D curve, it must be located on the shock, i.e., the 3D LE is one-to-one correspondence with its $2 \mathrm{D}$ projection at the base plane. Hence, each waverider can be defined by each 2D curve at the base plane actually.

The 2D definition curve is described by directly setting a series of data. On the contrary, the parameterization method may offer the more convenient and simpler way. Here the quadric function, the sigmoid function and the $\mathrm{B}$ spline function are included as parameterized functions. The formulations of them are given as follows:

$$
\begin{aligned}
& z=Z_{0}+A y^{2} \\
& z=Z_{0}+\frac{1}{1+\exp \left(y-Y_{0}\right)}
\end{aligned}
$$

$P(t)=\frac{1}{6}\left[\begin{array}{llll}t^{3} & t^{2} & t & 1\end{array}\right]\left[\begin{array}{cccc}-1 & 3 & -3 & 1 \\ 3 & -6 & 3 & 0 \\ -3 & 0 & 3 & 0 \\ 1 & 4 & 1 & 0\end{array}\right]\left[\begin{array}{l}P_{0} \\ P_{1} \\ P_{2} \\ P_{3}\end{array}\right]$,

$P(t)=(x(t), y(t)), \quad t \in[0,1]$,

$P_{i}=\left(X_{i}, Y_{i}\right), \quad i=0, \cdots, 3$.

Equations (1)-(3) are the quadric function, the sigmoid function, and the B spline function, respectively. In Eqs. (1) and (2), $Z_{0}, Y_{0}$ and $A$ are control variables. In Eq. (3), $P_{0}-P_{3}$ are control points. Obviously, whatever function is chosen, the shape of curve is only depended on several parameters.

\subsection{The lower and upper surface design}

No matter which type of definition curve is used, the lower surface of a waverider is created by tracing the streamlines. If the LE is taken the direction of tracing the streamlines is the freestream (Fig. 4a). Otherwise, the streamlines will be traced in the upwind direction if the definition curve is the profile of the scramjet's inlet. A streamline is depicted by the following equation:

$\frac{\mathrm{d} x}{u}=\frac{\mathrm{d} y}{v}=\frac{\mathrm{d} z}{w}=\mathrm{d} s$. 
Fig. 3 An example of 3D grid structure (a) and its profile at base plane (b) a

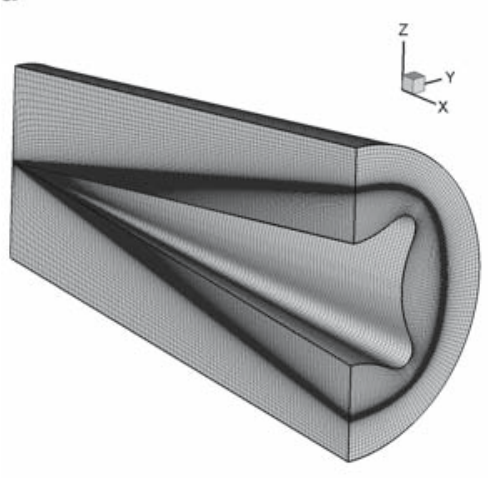

b

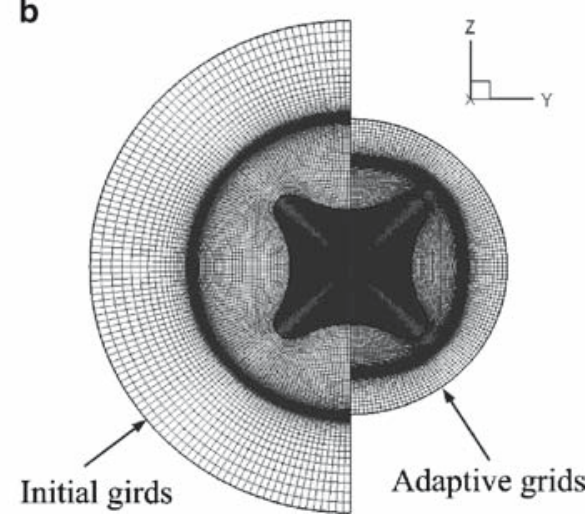

Fig. 4 The definition method of a waverider. a defined by the LE; $\mathbf{b}$ defined by the profile of the scramjet's inlet

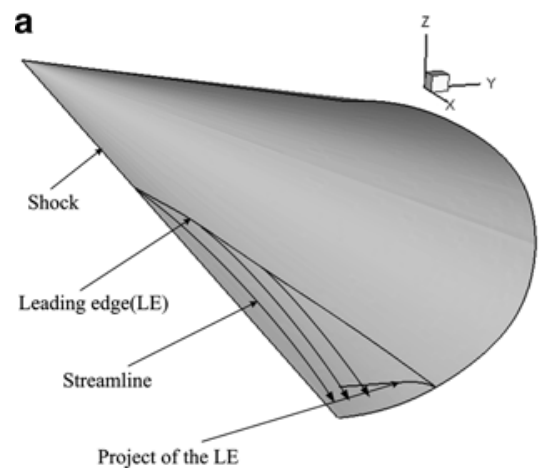

Equation (4) is an ordinary differential function, which can be solved easily by using the classic Runge-Kutta methods. The upper surface of the waverider is created by following the freestream through the LE to the base of the waverider.

Once the lower and the upper surface are constructed, the whole design procedure is almost finished. The work of the next logical stage is to evaluate the aerodynamic performance of the designed configurations. The numerical tools for the waverider's evaluation will be introduced in the next part.

\section{Aerodynamic performance evaluation tools}

Here, a 3D thin-layer Reynolds-averaged Navier-Stokes equations in strong conservation law form is employed to calculate the aerodynamic performance of waveriders. It can be formulated in curvilinear space $\xi, \eta, \zeta$ and $\tau$ (nondimensional form) as

$\partial_{\tau} \hat{Q}+\partial_{\xi} \hat{F}+\partial_{\eta} \hat{G}+\partial_{\zeta} \hat{H}=R e^{-1} \partial_{\xi} \hat{H}_{v}$,

where $\xi$ is in the streamwise direction, $\eta$ is in the circumferential direction in the cross-flow plane and $\zeta$ is in the normal direction from the body. $\hat{Q}$ represents the conserved variables, $\hat{F}, \hat{G}$ and $\hat{H}$ represent the inviscid fluxes. The viscosity coefficient $\mu$ and $\hat{H}_{v}$ are calculated by summing up the laminar and the turbulent viscosity coefficients and evaluated by the Sutherland's law and the Baldwin-Lomax model, respectively.
The LU-SGS method employing a Newton-like subiteration, developed by Yoon and Jameson [17], is used to solve the Eq. (5) numerically. Second-order temporal accuracy is obtained by utilizing three-point backward difference in the sub-iteration procedure. The numerical algorithm can be deduced as

$$
\begin{aligned}
\boldsymbol{L} \boldsymbol{D}^{-1} \boldsymbol{U} \Delta \boldsymbol{Q}= & -\phi^{i}\left\{(1+\phi) \boldsymbol{Q}^{p}-(1+2 \phi) \boldsymbol{Q}^{n}\right. \\
& +\phi \boldsymbol{Q}^{n-1}-\boldsymbol{J} \Delta \tau \boldsymbol{Q}^{p}\left[\left(\xi_{t} / \boldsymbol{J}\right)_{\xi}+\left(\eta_{t} / \boldsymbol{J}\right)_{\eta}\right. \\
& \left.+\left(\varsigma_{t} / \boldsymbol{J}\right)_{\varsigma}\right]^{p}+\boldsymbol{J} \Delta \tau\left[\delta_{\xi} \boldsymbol{F}^{p}+\delta_{\eta} \boldsymbol{G}^{p}\right. \\
& \left.\left.+\delta_{\varsigma}\left(\boldsymbol{H}^{p}-\boldsymbol{H}_{v}^{p}\right)\right]\right\}
\end{aligned}
$$

where

$$
\begin{aligned}
& \boldsymbol{L}=\bar{\rho} \boldsymbol{I}+\phi^{i} \boldsymbol{J} \Delta \tau\left(\boldsymbol{A}_{i-1, j, k}^{+}+\boldsymbol{B}_{i, j-1, k}^{+}+\boldsymbol{C}_{i, j, k-1}^{+}\right), \\
& \boldsymbol{D}=\bar{\rho} \boldsymbol{I}, \\
& \boldsymbol{U}=\bar{\rho} \boldsymbol{I}+\phi^{i} \boldsymbol{J} \Delta \tau\left(\boldsymbol{A}_{i+1, j, k}^{-}+\boldsymbol{B}_{i, j+1, k}^{-}+\boldsymbol{C}_{i, j, k+1}^{-}\right),
\end{aligned}
$$

and

$$
\begin{aligned}
& \bar{\rho}=1+\phi^{i} \boldsymbol{J} \Delta \tau[\bar{\rho}(\boldsymbol{A})+\bar{\rho}(\boldsymbol{B})+\bar{\rho}(\boldsymbol{C})], \\
& \phi^{i}=1 /(1+\phi), \quad \Delta \boldsymbol{Q}=\boldsymbol{Q}^{p+1}-\boldsymbol{Q}^{p},
\end{aligned}
$$

where $\phi=0.5$ and $p$ denotes the sub-iteration number. The deduced sub-iteration scheme reverts to the standard LU-SGS scheme for $\phi=0$ and $p=1$. In fact, second-order time accuracy maintains when the sub-iteration number tends to infinity, regardless of temporal accuracy of the left hand of Eq. (6). 


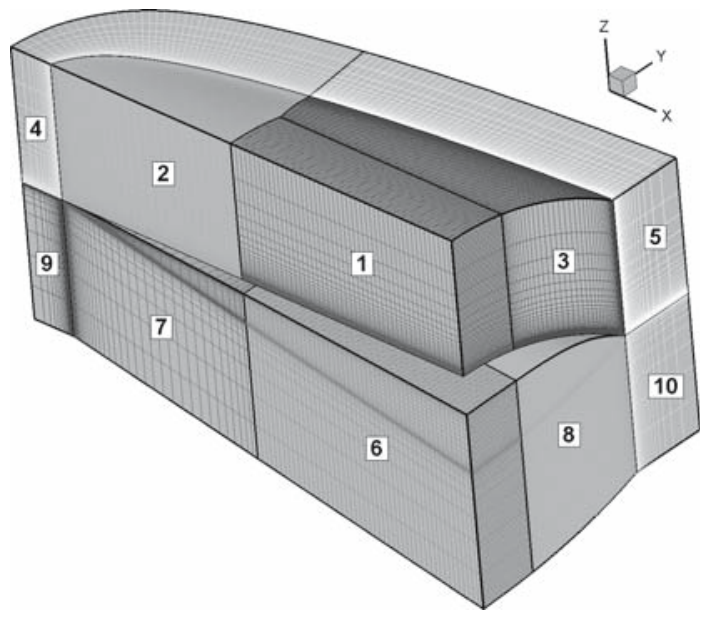

Fig. 5 Grid structure of the waverider

In Eq. (6), the inviscid terms are approximated by modified third-order upwind HLLEW scheme of Obayashi et al. [18]. For the isentropic flow, the scheme results in the standard upwind-biased flux-difference splitting scheme of Roe. As the jump in entropy become large in the flow, the scheme turns to the standard HLLEW scheme. Thin-layer viscous term in Eq. (6) is discretized by second-order central difference.

The grid used for this study is an $H$-type structural multiblock grid. The whole computational domain is divided into ten blocks. A typical grid distribution is shown in Fig. 5, and the grids near the wall and the shock are all refined for guarantee the computational accuracy.

\section{Numerical examples}

An integrated software package with the name of GCBWRG (General Cone-based Waverider Generator) is based on the above method. Three cases are carried out to test our method and program. The first case validates the CFD codes. The second case tests the waverider design method. The geometrical and aerodynamic performance of several waveriders derived from different cones are calculated and compared in the last case.

\subsection{Case 1}

The aerodynamic performance of a waverider configuration, same as in Ref. [19], is calculated to test the accuracy of our CFD codes. The shape of the waverider and the computational conditions are shown in Fig. 6 and Table 1, respectively.

Two groups of results are listed in Ref. [19], calculated by using the MAXWARP and developed by University of Maryland. In the MAXWARP, the inviscid pressure is obtained from the original generating flowfield, while the
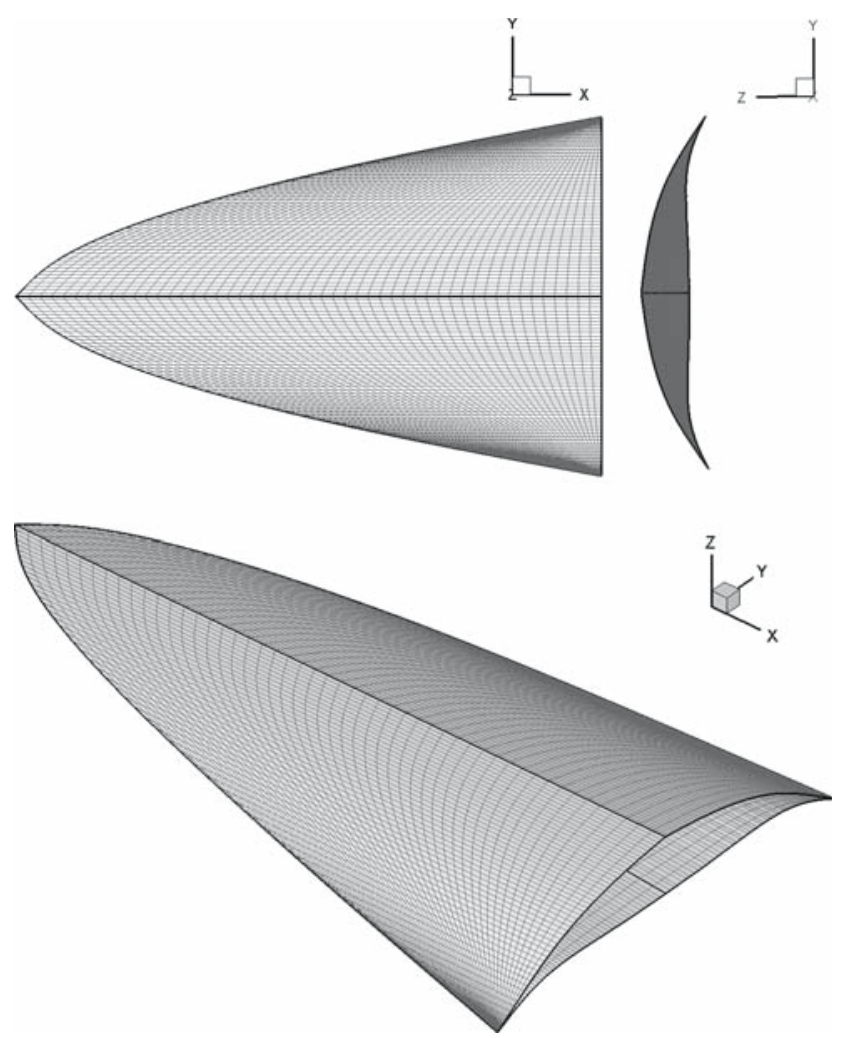

Fig. 6 The shape of the viscous optimized waverider [19]

Table 1 Computational conditions for Case 1

$M \quad \alpha_{\text {attack }} /\left(^{\circ}\right) \alpha_{\text {shock }} /\left(^{\circ}\right) \quad L / \mathrm{m} \quad H / \mathrm{km} \quad T_{\infty} / \mathrm{K} \quad T_{\mathrm{w}} / \mathrm{K} \quad R e$

\begin{tabular}{llllllll}
\hline 6.0 & 0.0 & 12.0 & 60.0 & 30.0 & 231.3 & 1100.0 & $1.294 \times 10^{8}$ \\
\hline
\end{tabular}

$M$ is the Mach number, $\alpha_{\text {attack }}$ is the angle of attack, $\alpha_{\text {shock }}$ is the shock angle, $L$ is the length of the waverider, $H$ is the flight altitude, $T_{\infty}$ is the static temperature, $T_{\mathrm{w}}$ is the wall temperature and $R e$ is the Reynolds number

Table 2 Aerodynamic performance of viscous optimized waverider by different solvers

\begin{tabular}{llll}
\hline Code & MAXWARP & CFL3D & GCBWRG \\
\hline$C_{l}$ & $3.168 \times 10^{-2}$ & $3.228 \times 10^{-2}$ & $3.318 \times 10^{-2}$ \\
$C_{d}$ & $4.089 \times 10^{-3}$ & $4.391 \times 10^{-3}$ & $4.353 \times 10^{-3}$ \\
$L / D$ & 7.74 & 7.35 & 7.62 \\
\hline
\end{tabular}

skin friction is estimated by using the reference temperature method. The other group of results are obtained by using the CFL3D, which is a thin layer 3D Navier-Stokes equations solver developed by NASA Langley Research Center. Table 2 shows the above two groups of the results and one group of our results. Table 3 shows the difference of computational results between every two solvers. 
Table 3 Difference of computational results by different solvers

\begin{tabular}{llll}
\hline & $\left|\frac{\text { CFL3D - MAXWARP }}{\text { CFL3D }}\right|(\%)$ & $\left|\frac{\text { GCBWRG - MAXWARP }}{\text { GCBWRG }}\right|(\%)$ & $\left|\frac{\text { GCBWRG - CFL3D }}{\text { GCBWRG }}\right|(\%)$ \\
\hline$C_{l}$ & 1.86 & 4.52 & 2.71 \\
$C_{d}$ & 6.87 & 6.06 & 0.87 \\
$L / D$ & 5.31 & 1.57 & 3.54 \\
\hline
\end{tabular}

Fig. 7 Waverider configurations. a Configuration 1; b Configuration 2; c Configuration 3

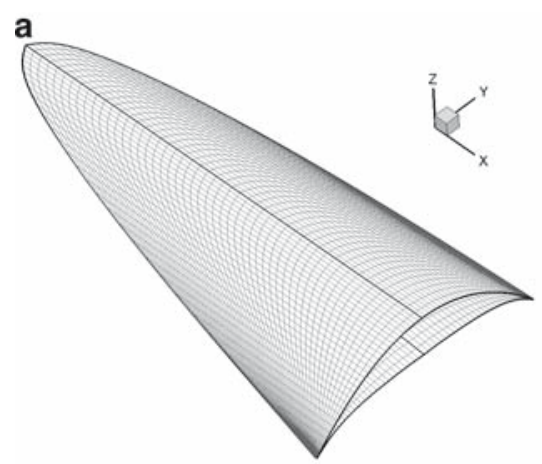

b

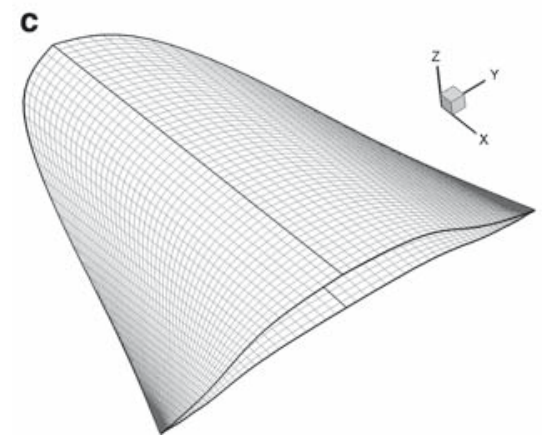

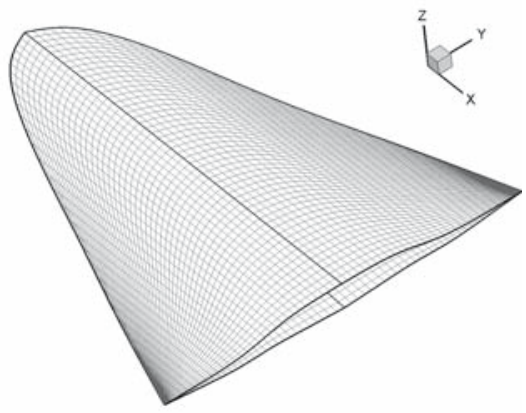

In the above two tables, $C_{l}, C_{d}$, and $L / D$ denote the lift coefficient, the drag coefficient and the lift to drag ratio, respectively. On the basis of the results of Tables 2 and 3, we know that the computational errors are acceptable for all aerodynamic coefficients. These results demonstrate the reliability of our codes.

\subsection{Case 2}

The main objective of the second case is validate the method above. Three configurations are included in this case (Fig. 7). The corresponding generating bodies are shown in Figs. 2b,c,d. All waverider definition and curve depiction methods are employed in the above Eqs. (1)-(3). Some relative information about the waverider definition is presented in Table 4. The detail information about the generating bodies is presented in Appendix 1. The data for defining these waveriders are presented in Appendix 2.

The design condition is set on the flight speed of Mach 6 and the flight altitude of $30 \mathrm{~km}$. The value of static temperature is $231.3 \mathrm{~K}$. The length of all the three configurations is $3 \mathrm{~m}$. The Reynolds number based on this length is about $7 \times 10^{6}$. A grid dimension of $31 \times 49 \times 49$ is used for blocks No. 4, 5, 9 and 10. For the rest blocks, the grid dimension was set to $49 \times 49 \times 49$.

Figure 8 shows the pressure contours at the base plane. These figures clearly show that the high pressure zone is almost entirely covered by the lower surface of the waverider
Table 4 Information about waverider definitions

\begin{tabular}{lllll}
\hline No. & Configuration & Generating body & Waverider definition method & Definition curve \\
\hline 1 & Fig. 7a & Fig. $2 \mathrm{~b}$ & The LE & The quadric function \\
2 & Fig. $7 \mathrm{~b}$ & Fig. $2 \mathrm{c}$ & The LE & The sigmoid function \\
3 & Fig. $7 \mathrm{c}$ & Fig. $2 \mathrm{~d}$ & Profile of scramjet's inlet & The B spline function \\
\hline
\end{tabular}


Fig. 8 Pressure contours of different waveriders (at the base plane). a Configuration 1; b Configuration 2; c Configuration 3 a

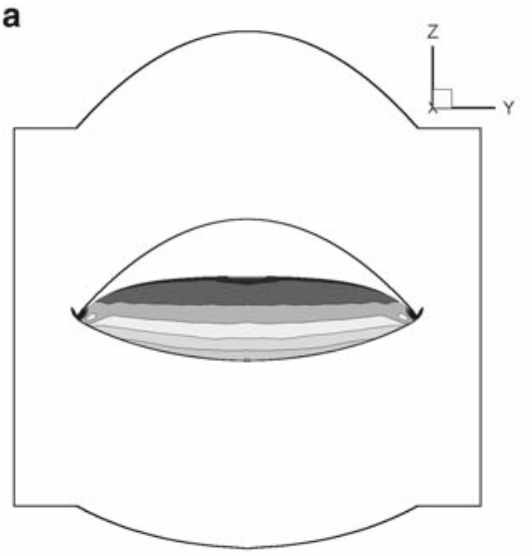

b

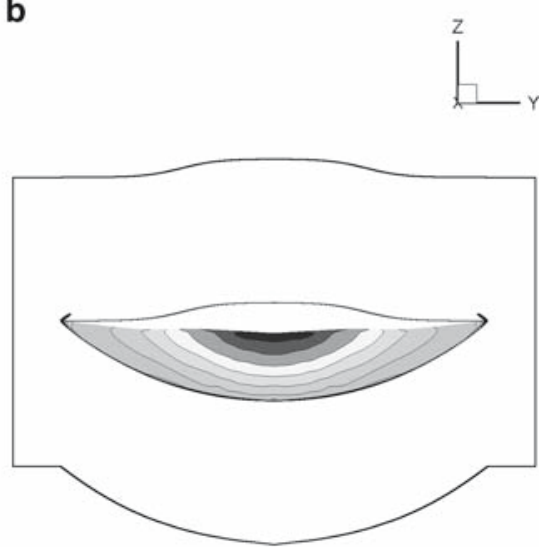

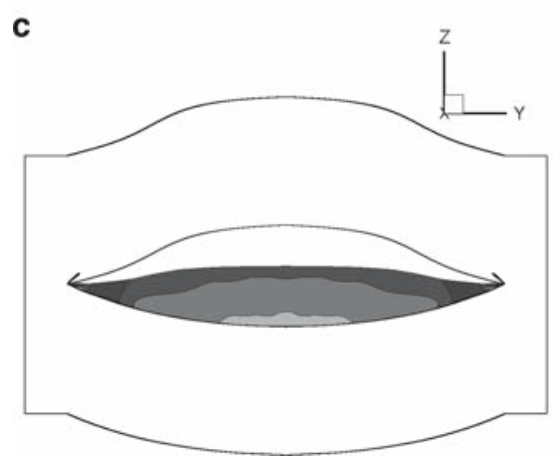

when flight at its design point. These results demonstrate that both the method and the program are successful. Table 5 shows the $L / D$ for each configuration of Fig. $7, P_{\text {base }}$ is the pressure of the base section.

\subsection{Case 3}

The four cones shown in Fig. 2 are taken as the generating bodies, and the four configurations are generated accordingly. The design point and the computational conditions are the same as Case 2.

To ensure the comparability of the four configurations, a similar definition method of the LE is adopted, shown in Fig. 9. The two dimensional projection of the LE at $Y Z$ plane is a line, and the normal distance between the LE and the lowest position of the shock layer is 5 units. The length of the cone is 100 . The $3 \mathrm{D}$ views of the four configurations are shown in Fig. 10. The length of the waveriders is taken as the characteristic size and set to 1 . All the above data are dimensionless. Tables 6 and 7 list the geometrical and aerodynamic parameters in relation to the above configurations, respectively.

In Table $7, C_{l \text { inf }}, C_{d \text { inf }}$ and $L / D_{\text {inf }}$ are the lift coefficient, the drag coefficient and the ratio of lift to drag without base $\operatorname{drag}\left(P_{\text {base }}=P_{\infty}\right)$, respectively, while $C_{f 0}, C_{d 0}$ and $L / D_{0}$ are the lift coefficient, drag coefficient and the ratio of lift to drag with base drag $\left(P_{\text {base }}=0\right)$, respectively. It is obviously
Table 5 The $L / D$ of waveriders

\begin{tabular}{llll}
\hline$P_{\text {base }}$ & No.1 & No.2 & No.3 \\
\hline$P_{\infty}$ & 7.20 & 7.08 & 7.03 \\
0 & 4.52 & 4.24 & 4.47 \\
\hline
\end{tabular}

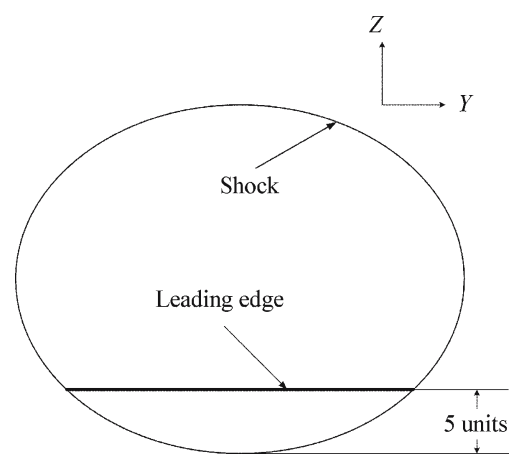

Fig. 9 Definition of the LE of Case 3

that the geometrical and the aerodynamic parameters of the four configurations are different. The results can provide the helpful references for practical designs on different purposes. For instance, the floriated cone-derived waverider will be a competitive candidate with the large volumetric efficiency if the high cubage is needed to design a vehicle. If we need to 
a

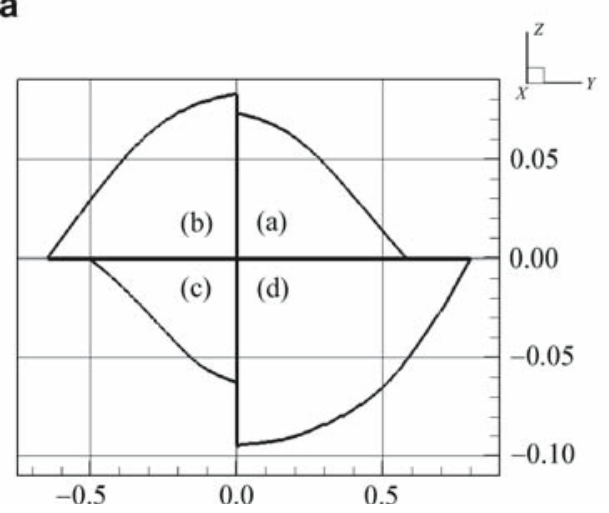

b

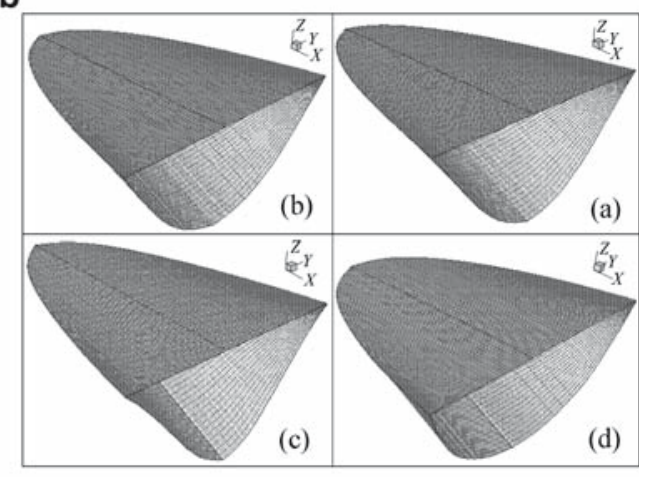

Fig. 10 The 2D (left) and 3D (right) views of different cone-derived waveriders. a the circle cone derived waverider; $\mathbf{b}$ the quadrate cone derived waverider; $\mathbf{c}$ the cross cone derived waverider; $\mathbf{d}$ the floriated cone derived waverider

Table 6 Dimensionless geometrical parameters of the different cone-derived waveriders

\begin{tabular}{lllllllll}
\hline No. & $V$ & $S$ & $S_{x}$ & $S_{y}$ & $S_{z}$ & $W$ & $T_{c}$ & $\eta_{V}$ \\
\hline 1 & $6.48 \times 10^{-3}$ & $7.45 \times 10^{-1}$ & $2.58 \times 10^{-2}$ & $3.43 \times 10^{-2}$ & $3.71 \times 10^{-1}$ & $5.79 \times 10^{-1}$ & $7.34 \times 10^{-2}$ & $9.37 \times 10^{-2}$ \\
2 & $8.69 \times 10^{-3}$ & $8.45 \times 10^{-1}$ & $3.44 \times 10^{-2}$ & $3.94 \times 10^{-2}$ & $4.20 \times 10^{-1}$ & $6.48 \times 10^{-1}$ & $8.33 \times 10^{-2}$ & $10.0 \times 10^{-2}$ \\
3 & $4.30 \times 10^{-3}$ & $6.42 \times 10^{-1}$ & $1.72 \times 10^{-2}$ & $2.87 \times 10^{-2}$ & $3.20 \times 10^{-1}$ & $5.05 \times 10^{-1}$ & $6.25 \times 10^{-2}$ & $8.26 \times 10^{-2}$ \\
4 & $13.5 \times 10^{-3}$ & $10.8 \times 10^{-1}$ & $5.27 \times 10^{-2}$ & $4.60 \times 10^{-2}$ & $5.35 \times 10^{-1}$ & $7.97 \times 10^{-1}$ & $9.48 \times 10^{-2}$ & $10.6 \times 10^{-2}$
\end{tabular}

$V$ the volume of the configuration; $S$ the total surface area; $S_{x}, S_{y}$ and $S_{z}$ the projective area at $X, Y$ and $Z$ direction, respectively; $W$ the wingspan; $T_{c}$ the thickness of configurations at centerline; $\eta_{V} V^{2 / 3} / S_{z}$ the volumetric efficiency

pursue the lowest drag, the cross cone-derived configuration is recommended.

\section{Conclusions}

A flexible method and the relevant software package based on the CFD analysis are developed to design a waverider. A class of general cone-derived configurations are generated by employing this method. Either the LE or the profile of the scramjet's inlet can be used to define the waveriders. Moreover, various methods are imported to parameterize the definition curves, which offers a convenient way for sketching the definition curves.

Several numerical examples are used to validate the method and the codes. The results show that all the designs are successful. Furthermore, four configurations derived from different cones are compared at Mach 6. The corresponding results demonstrate that the waveriders present the different geometrical and aerodynamic performances. Moreover, several primary suggestions are proposed for the practical designs.

In the present paper, the different cone-derived waveriders are compared. In fact, the available candidates of the generating cones are almost infinite. We think that deep and detailed comparisons will deduce more general rules. The
Table 7 Aerodynamic parameters of different cone-derived waveriders

\begin{tabular}{lllllll}
\hline No. & $C_{l \text { inf }}$ & $C_{d \text { inf }}$ & $L / D_{\text {inf }}$ & $C_{l 0}$ & $C_{d 0}$ & $L / D_{0}$ \\
\hline 1 & 0.4316 & 0.05936 & 7.27 & 0.4316 & 0.09904 & 4.36 \\
2 & 0.4492 & 0.06266 & 7.17 & 0.4492 & 0.10234 & 4.39 \\
3 & 0.4114 & 0.05850 & 7.03 & 0.4114 & 0.09819 & 4.19 \\
4 & 0.4753 & 0.06918 & 6.87 & 0.4753 & 0.10886 & 4.37 \\
\hline
\end{tabular}

other content of our research is to optimize the waveriders. The investigations are underway.

\section{Appendix 1}

The length of the four generating cones in Fig. 2 is 100 (dimensionless). The profile (at $x=100$ ) of the first cone Fig. $2 \mathrm{a}$ is a circle with the radius of 12.44 , while the profiles (at $x=100$ ) of the other three cones are defined by the B-spline function. The numbers of the control points in the $\mathrm{B}$-spline function and the relevant values at $Y$ and $Z$ axes are shown in the Table 8.

\section{Appendix 2}

The definition curves (the 2D projection at the base plane) for the three configurations in Case 2 are defined as follows. The 
Table 8 The numbers of the control points and the relevant values in the $B$-spline function at $Y$ and $Z$ axes

\begin{tabular}{lll}
\hline Figures & $\begin{array}{l}\text { Numbers of control } \\
\text { points }\end{array}$ & Control points values of $Y$ and $Z$ \\
\hline bb & 10 & $(0,12.44),(2,12.44),(5,12.44),(8,12.44),(10,12.44)$, \\
& & $(12.44,10),(12.44,8),(12.44,5),(12.44,2),(12.44,0)$ \\
& $(0,12.44),(1,12.44),(2,12.44),(3,12.44),(4,12.44),(4,10)$, \\
$2 \mathrm{c}$ & 17 & $(4,8),(4,6),(4,4),(6,4),(8,4),(10,4),(12.44,4)$, \\
& & $(12.44,3),(12.44,2),(12.44,1),(12.44,0)$ \\
& & $(0,12.44),(1,12.44),(2,12.44),(5,13),(8,14),(12,16),(15,15)$, \\
$2 \mathrm{~d}$ & 13 & $(16,12),(14,8),(13,5),(12.44,2),(12.44,1),(12.44,0)$
\end{tabular}

LE of Configuration 1 is depicted by the quadric function with Eq. (1), where the parameters $Z_{0}=-13$ and $A=-0.05$. The LE of Configuration 2 is depicted by the sigmoid function with Eq. (2), where $Z_{0}=-16$ and $Y_{0}=-5$. The profile of the scramjet's inlet of Configuration 3 is depicted by the B-spline function, where four control points are used and the coordinate values are $(0,-20),(7,-20),(10,-21)$ and $(13,-21)$.

\section{References}

1. Bowcutt K.G., Anderson J.D., Capriotti D.: Viscous optimized hypersonic waveriders. AIAA Paper 87-0272 (1987)

2. Nonweiler, T.R.F.: Aerodynamic problems of manned space vehicles. J. Roy. Aeronaut. Soc. 63, 521-530 (1959)

3. Jones, J.G., Moore, K.C., Pike, J., et al.: A method for designing lifting configurations for high supersonic speeds, using axisymmetric flow fields. Ingenieur-Archiv, 37, 56-72 (1968)

4. Rasmussen, M.L.: Waverider configurations derived from inclined circular and elliptic cones. J. Spacecraft Rockets 17(6), 537-545 (1980)

5. Rasmussen, M.L., Clement, L.W.: Cone-derived waveriders with longitudinal curvature. AIAA Paper pp. 84-2100 (1984)

6. Doty, R.T., Rasmussen, M.L.: Approximation for hypersonic flow past an inclined cone. AIAA J. 11, 1310-1315 (1973)

7. Corda, S., Anderson, J.D.: Viscous optimized hypersonic waveriders designed from axisymmetric flowfields. AIAA Paper pp. 88-0369 (1988)

8. Takashima, N., Lewis, M.J.: A cone-wedge waverider configuration for engine-airframe integration. J. Aircraft 32(5), 1142-1144 (1995)
9. Sabean, J.W., Lewis, M.J., Mee, D., et al.: Performance study of a power law star body. AIAA Paper pp. 98-1617 (1998)

10. Goonko, Y.P., Mazhul, I.I., Markelov, G.N.: Convergent-flowderived waveriders. J. Aircraft 37(4), 647-654 (2000)

11. Jones, K.D., Sobieczky, H., Seebass, A.R., et al.: Waverider design for generalized shock geometries. J. Spacecraft Rockets 32(6), 957-963 (1995)

12. Miller R.W., Argrow B.M., Center K.B., et al.: Experimental verification of the osculating cones method for two waverider forebodies at Mach 4 and Mach 6. AIAA Paper pp. 98-0682 (1998)

13. Takashima, N., Lewis, M.J.: Optimization of waverider-based hypersonic cruise vehicles with off-design considerations. J. Aircraft 36(1), 235-245 (1999)

14. Rodi, D.P.E.: The osculating flowfield method of waverider geometry generation. AIAA Paper pp. 2005-0511 (2005)

15. Lewis, M.J., Chauffour, M.L.: Shock-based waverider design with pressure gradient corrections and computational simulations. J. Aircraft 42(5), 1350-1352 (2005)

16. Yang, G.W., Kondo, M., Obayashi, S.: Multiblock Navier-Stokes solver for wing/fuselage transport aircraft. JSME Int. J. 45(1), 85-90 (2002)

17. Yoon, S., Jameson, A.: Lower-supper symmetric - Gauss-Seidel method for the Euler and Navier-Stokes equations. AIAA J. 26, 1025-1026 (1988)

18. Obayashi, S., Guruswamy, G.P.: Convergence acceleration of a Navier-Stokes solver for efficient static aeroelastic computations. AIAA J. 33, 1134-1141 (1995)

19. Takashima, N., Lewis, M.J.: Navier-Stokes computation of a viscous optimized waverider. J. Spacecraft Rockets 31(3), 383391 (1994) 